Research Paper

\title{
A Novel Prognostic Score, Based on Preoperative Nutritional Status, Predicts Outcomes of Patients after Curative Resection for Gastric Cancer
}

\author{
Xuechao Liu ${ }^{1,2 *}$, Haibo Qiu ${ }^{1,2 *}$, Jianjun Liu ${ }^{1,2}$, Shangxiang Chen ${ }^{1,2}$, Dazhi $\mathrm{Xu}^{1,2}$, Wei $\mathrm{Li}^{1,2}$, Youqing Zhan ${ }^{1,2}$, \\ Yuanfang Li1 ${ }^{1,2}$, Yingbo Chen ${ }^{1,2}$, Zhiwei Zhou ${ }^{1,2}$, Xiaowei Sun ${ }^{1,2} \llbracket$ \\ 1. Sun Yat-sen University Cancer Center; State Key Laboratory of Oncology in South China; Collaborative Innovation Center for Cancer Medicine, Guangzhou \\ 510060, China; \\ 2. Department of Gastric and Pancreatic Surgery, Sun Yat-sen University Cancer Center, Guangzhou, China. \\ * Xuechao Liu and Haibo Qiu contributed equally to this work. \\ $\square$ Corresponding author: Xiaowei Sun, Department of Gastric and Pancreatic Surgery, Sun Yat-sen University Cancer Center, Guangzhou, China, 651\# East \\ Dongfeng road, Guangzhou 510060, Guangdong Province, China. Fax: (+86) 020-87343123. E-mail: sunxw@sysucc.org.cn.
}

(1) Ivyspring International Publisher. Reproduction is permitted for personal, noncommercial use, provided that the article is in whole, unmodified, and properly cited. See http://ivyspring.com/terms for terms and conditions.

Received: 2016.06.12; Accepted: 2016.09.04; Published: 2016.10.25

\begin{abstract}
PURPOSE: We aimed to determine whether preoperative nutritional status (PNS) was a valuable predictor of outcome in patients with gastric cancer (GC).

METHODS: We retrospectively evaluated 1320 patients with GC undergoing curative resection. The PNS score was constructed based on four objective and easily measurable criteria: prognostic nutritional index (PNI) score 1, serum albumin $<35 \mathrm{~g} / \mathrm{L}$, body mass index (BMI) $<18.5 \mathrm{~kg} / \mathrm{m}^{2}$, or preoperative weight loss $\geq 5 \%$ of body weight. The PNS score was 2 for patients who met three or four criteria, 1 for those who met one or two criteria, and 0 for those who didn't meet all of these criteria.

RESULTS: The overall survival (OS) rates in patients with PNS scores 0,1 , and 2 were $59.1 \%$, $42.4 \%$, and $23.4 \%$, respectively $(P<0.001)$. Multivariate analyses revealed the PNS was an independent predictor for OS (HR for PNS 1 and PNS 2: 1.497, $95 \% \mathrm{Cl}: 1.230-1.820$ and 2.434, 95 $\%$ Cl: 1.773-3.340, respectively; $\mathrm{p}<0.001$ ). Furthermore, 5-year OS ranged from $92 \%$ (stage I) to $37 \%$ (stage III), while the combination of TNM and PNS stratified 5-year OS from 95\% (TNM I, PNS 0) to 19\% (TNM III, PNS 3). Of note, the prognostic significance of PNS was still maintained when stratified by TNM stage, age, sex, tumor size, anemia and adjuvant chemotherapy (All $P<0.05$ ).

CONCLUSIONS: The PNS, a novel nutritional-based prognostic score, is independently associated with OS in GC. Prospective studies are needed to validate its clinical utility.
\end{abstract}

Key words: preoperative nutritional status; prognosis; gastric cancer; adjuvant chemotherapy

\section{Introduction}

Gastric cancer (GC) is one of the most common malignancies worldwide, accounting for approximately one million new cases annually $[1,2]$. Despite great advancements in early detection, surgical techniques, and multidisciplinary treatment in recent years, the postoperative long-term survival of patients is still poor [3]. Therefore, there is increasing interest in prognostic factors to accurately identify patients at high risk of recurrence and cancer death.

Cancer-associated malnutrition is common in the majority of patients with cancer, which affects their quality of life, response to anticancer treatment and survival [4, 5]. Over the past decades, the 
relationship between malnutrition and patient outcome has been well established in many cancers [6-9]. Several preoperative nutritional-based scores are designed in order to evaluate nutritional risk, postoperative complications and long-term prognosis, such as the Nutritional Risk Index, Mini Nutritional Assessment, and Geriatric assessment [10-12]. Despite recommendations, they fail to gain widespread consensus in GC. To seek a more practical and ideal method for classifying nutritional status, we used some objective and easily measurable criteria: prognostic nutritional index (PNI), serum albumin, body mass index (BMI), and preoperative weight loss. In fact, these scoring systems have been well validated as independent predictor of postoperative survival in GC. One meta-analysis of 14 studies suggested that PNI might be a valuable predictive indicator for the outcome of cancer, especially digestive system carcinomas [13]. Study of Lien et al revealed that serum albumin levels were independent factors correlated with prognosis in GC [14]. A recent study, including 1249 cases, shown that a low BMI was associated with poorer prognosis in stage III-IV GC patients [15]. Furthermore, our previous study reported that preoperative weight loss independently predicted overall survival (OS) in GC [16]. We postulated that, when combined, these four markers might better reflect the balance of nutritional status than when used alone.

In present study, we developed a new combination scoring system based on preoperative nutritional status (PNS). We aimed to validate the PNS score with a retrospective study and investigate its clinical utility in GC.

\section{Material and methods}

\section{Patient selection}

We retrospectively reviewed clinicopathological data from 1320 patients with GC undergoing curative D2 resection at Sun Yat-sen University Cancer Center between January 2001 and December 2012. D2 lymphadenectomy was performed according to the Japanese Research Society for Gastric Cancer (JRSGC) guidelines [17].

The inclusion criteria were as follow: (1) histologically confirmed stage I through III gastric adenocarcinoma, (2) no parenteral nutrition within one month before surgery, (3) no neoadjuvant chemotherapy or radiotherapy, and (4) entire set of clinicopathological and follow-up data.

We retrospectively reviewed the patients' medical records to gather specific data, such as age, gender, height, body weight, preoperative laboratory test, surgical pathology report and survival times.
Blood samples were collected within two weeks before surgery. Tumors were staged using the seventh edition of the American Joint Committee on Cancer (AJCC) tumor-nodes-metastasis (TNM) staging system [18]. In accordance with current clinical guidelines, postoperative patients with stage II-III GC and no marked comorbidities precluding chemotherapy use were offered 5-fluorouracil-based adjuvant chemotherapy [19, 20]. Our study was approved by the Sun Yat-sen University Cancer Center research ethics committee.

\section{Follow-up}

All patients were routinely followed every 3 months in the first 2 years after surgery and every 6 months thereafter, including physical examination, laboratory testing, dynamic CT scan and upper gastrointestinal endoscopy. The latest follow-up was June, 2015 and the median follow-up duration was 35 months (range 1-160). OS was calculated from the date of surgery until death or the last available follow-up.

\section{Nutritional-based indices}

The prognostic nutritional index (PNI) was calculated as follows: patients with a combined albumin $(\mathrm{g} / \mathrm{L}) \times$ total lymphocyte count $\times 10^{9} / \mathrm{L} \geq 45$ were assigned a PNI of 0 . Patients in whom this total score was $<45$ were assigned a PNI of 1 [21].

Serum albumin was carried out using standard threshold.

The BMI was calculated as previously reported $\left(<18.5 \mathrm{~kg} / \mathrm{m}^{2}, \geq 18.5\right.$ to $\left.<25.0 \mathrm{~kg} / \mathrm{m}^{2}, \geq 25.0 \mathrm{~kg} / \mathrm{m}^{2}\right)$ and the preoperative body weight loss was categorized as " $<5 \%$ of body weight" or " $\geq 5 \%$ of body weight" $[15,22]$.

The PNS score was derived from four objective and easily measurable criteria: PNI score 1 , serum albumin $<35 \mathrm{~g} / \mathrm{L}, \mathrm{BMI}<18.5 \mathrm{~kg} / \mathrm{m}^{2}$, or preoperative weight loss $\geq 5 \%$ of body weight. The PNS score was 2 for patients who met three or four criteria, 1 for those who met one or two criteria, and 0 for those who didn't meet all of these criteria.

\section{Statistical analysis}

The association of the PNS score with various clinicopathological variables was analyzed using the chi-square test. Cumulative survival was estimated by the Kaplan-Meier method, and the statistical significance of differences was assessed by the log-rank test. The multivariate Cox proportional hazard model was applied for variables that proved to be significant $(P<0.05)$ in the univariate analysis. All clinicopathological variables were assessed for interaction and co-linearity. Statistical analyses were 
performed by SPSS 19.0 software (IBM Corporation, Armonk, NY, USA). Differences at P-values less than 0.05 were considered to be statistically significant.

\section{Results}

A total of 1320 GC patients were enrolled, 899 $(68.1 \%)$ patients were males and $421(31.9 \%)$ were females. The mean age of the patients was 59 years (range 19-89 years). Of these, $220(16.7 \%)$ patients had stage I GC, 331 (25.1\%) patients had stage II GC, and $769(58.3 \%)$ patients had stage III GC. During the follow-up period, $519(39.3 \%)$ patients died, and 801 $(60.7 \%)$ were alive at last follow-up. We divided the patients into three independent groups by PNS score. There were 511 patients with PNS 0, 722 patients with PNS 1 and 87 patients with PNS 2 (Table 1).

Table 1. General characteristics of 1320 gastric cancer patients.

\begin{tabular}{|c|c|}
\hline & No. of patients (\%) \\
\hline \multicolumn{2}{|l|}{ Age (years) } \\
\hline$<60$ & $697(52.8 \%)$ \\
\hline$\geq 60$ & $623(47.2 \%)$ \\
\hline \multicolumn{2}{|l|}{ Sex } \\
\hline Female & $421(31.9 \%)$ \\
\hline Male & $899(68.1 \%)$ \\
\hline \multicolumn{2}{|l|}{ Tumor size (cm) } \\
\hline$<5$ & $735(55.7 \%)$ \\
\hline$\geq 5$ & $585(44.3 \%)$ \\
\hline \multicolumn{2}{|c|}{ Tumor location Upper third } \\
\hline & $508(38.5 \%)$ \\
\hline Middle third & $273(20.7 \%)$ \\
\hline Lower third & $539(40.8 \%)$ \\
\hline \multicolumn{2}{|l|}{ Histological grade } \\
\hline Well differentiated & $223(16.9 \%)$ \\
\hline Poorly differentiated & $1097(83.1 \%)$ \\
\hline \multicolumn{2}{|l|}{ Anemia } \\
\hline No & $921(69.8 \%)$ \\
\hline Yes & $399(30.2 \%)$ \\
\hline \multicolumn{2}{|l|}{ PNI } \\
\hline 0 & $1178(89.2 \%)$ \\
\hline 1 & $142(10.8 \%)$ \\
\hline \multicolumn{2}{|l|}{$\mathrm{BMI}\left(\mathrm{Kg} / \mathrm{m}^{2}\right)$} \\
\hline$<18.5$ & $545(41.3 \%)$ \\
\hline $18.5 \leq$ and $<25.0$ & $439(33.3 \%)$ \\
\hline $25.0 \leq$ & $336(25.5 \%)$ \\
\hline \multicolumn{2}{|l|}{ Serum albumin (g/L) } \\
\hline$<35$ & $1201(91.0 \%)$ \\
\hline$\geq 35$ & $119(9.0 \%)$ \\
\hline \multicolumn{2}{|c|}{ Preoperative body weight loss } \\
\hline$<5 \%$ & $898(68.0 \%)$ \\
\hline$\geq 5 \%$ & $422(32.0 \%)$ \\
\hline \multicolumn{2}{|l|}{ PNS } \\
\hline 0 & $511(38.7 \%)$ \\
\hline 1 & $722(54.7 \%)$ \\
\hline 2 & $87(6.6 \%)$ \\
\hline \multicolumn{2}{|l|}{ TNM stage } \\
\hline I & $220(16.7 \%)$ \\
\hline II & $331(25.1 \%)$ \\
\hline III & $769(58.3 \%)$ \\
\hline \multicolumn{2}{|c|}{ Adjuvant chemotherapy } \\
\hline No & $811(61.4 \%)$ \\
\hline Yes & $509(38.6 \%)$ \\
\hline
\end{tabular}

The OS rates in patients with PNS scores 0, 1, and 2 were $59.1 \%, 42.4 \%$, and $23.4 \%$, respectively ( $\mathrm{P}<$ 0.001). Patients with a PNS of 0 (107.5 months) had significantly longer mean survival compared with patients with a PNS of 1 (86.1 months) or 2 (53.3 months) $(\mathrm{P}<0.001$; Table 2). Furthermore, OS at 5 years ranged from $92 \%$ (stage I) to $37 \%$ (stage III) and from $66 \%$ (PNS 0) to $30 \%$ (PNS 2). The combination of TNM and PNS stratified 5-year OS from 95\% (TNM I, PNS 0) to $19 \%$ (TNM III, PNS 3) $(\mathrm{P}<0.05)$.

Table 2. Overall survival based on five nutritional-based scores in 1320 gastric cancer patients.

\begin{tabular}{|c|c|c|c|}
\hline & & OS (months) & \\
\hline & Patients [n (\%)] & mean $(95 \% \mathrm{CI})$ & P-valuea \\
\hline PNI & & & $<0.001$ \\
\hline 0 & $1178(89.2)$ & $95.6(90.9,100.3)$ & \\
\hline 1 & $142(10.8)$ & $65.8(54.0,77.6)$ & \\
\hline BMI (Kg/m2) & & & 0.041 \\
\hline$<18.5$ & $545(41.3)$ & $89.6(82.8,96.3)$ & \\
\hline $18.5 \leq$ and $<25.0$ & $439(33.3)$ & $89.8(82.4,97.2)$ & \\
\hline $25.0 \leq$ & $336(25.5)$ & $96.3(88.3,104.4)$ & \\
\hline Serum albumin $(\mathrm{g} / \mathrm{L})$ & & & $<0.001$ \\
\hline$<35$ & $1201(91.0)$ & $94.5(89.9,99.1)$ & \\
\hline$\geq 35$ & $119(9.0)$ & $65.7(52.2,79.2)$ & \\
\hline Preoperative body weight loss & & & $<0.001$ \\
\hline$<5 \%$ & $898(68.0)$ & $101.7(96.4,107.0)$ & \\
\hline$\geq 5 \%$ & $422(32.0)$ & $70.5(63.4,77.6)$ & \\
\hline PNS & & & $<0.001$ \\
\hline 0 & $511(38.7)$ & $107.5(100.6,114.3)$ & \\
\hline 1 & $722(54.7)$ & $86.1(80.1,92.0)$ & \\
\hline 2 & $87(6.6)$ & $53.3(39.9,66.8)$ & \\
\hline
\end{tabular}

Abbreviations: PNI = Prognostic Nutritional Index; BMI = body mass index; PNS = Preoperative nutritional status; a Kaplan-Meier survival analysis.

The relationship between the PNS and clinicopathologic characteristics was shown in Table 3. An elevated PNS was associated with age $\geq 60$ years $(\mathrm{p}=0.015)$, male patients $(\mathrm{p}<0.001)$, larger tumor size $(p<0.001)$, presence of anemia $(p<0.001)$, and higher TNM stage $(p<0.001)$. However, PNS scores were not associated with tumor location, histological grade or adjuvant chemotherapy.

Univariate analysis showed that 10 clinicopathological variables were associated with OS (Table 4). After excluding correlated variables, six remaining variables were tested in the multivariate analysis. The multivariate analysis showed that the PNS was an independent predictor for OS (HR for PNS 1 and PNS 2: 1.497, $95 \%$ CI: $1.230-1.820$ and 2.434, 95 \% CI: 1.773-3.340, respectively; $\mathrm{p}<0.001$ ), along with age $(\mathrm{p}<0.001)$, tumor location $(\mathrm{p}<0.001)$, histological grade $(\mathrm{p}=0.047)$ and TNM stage $(\mathrm{P}<$ 0.001). In stage-matched analysis, the PNS was still associated with OS in stage I-II and stage III $(\mathrm{P}=0.019$ and $\mathrm{P}<0.001$, respectively; Figure 1). 


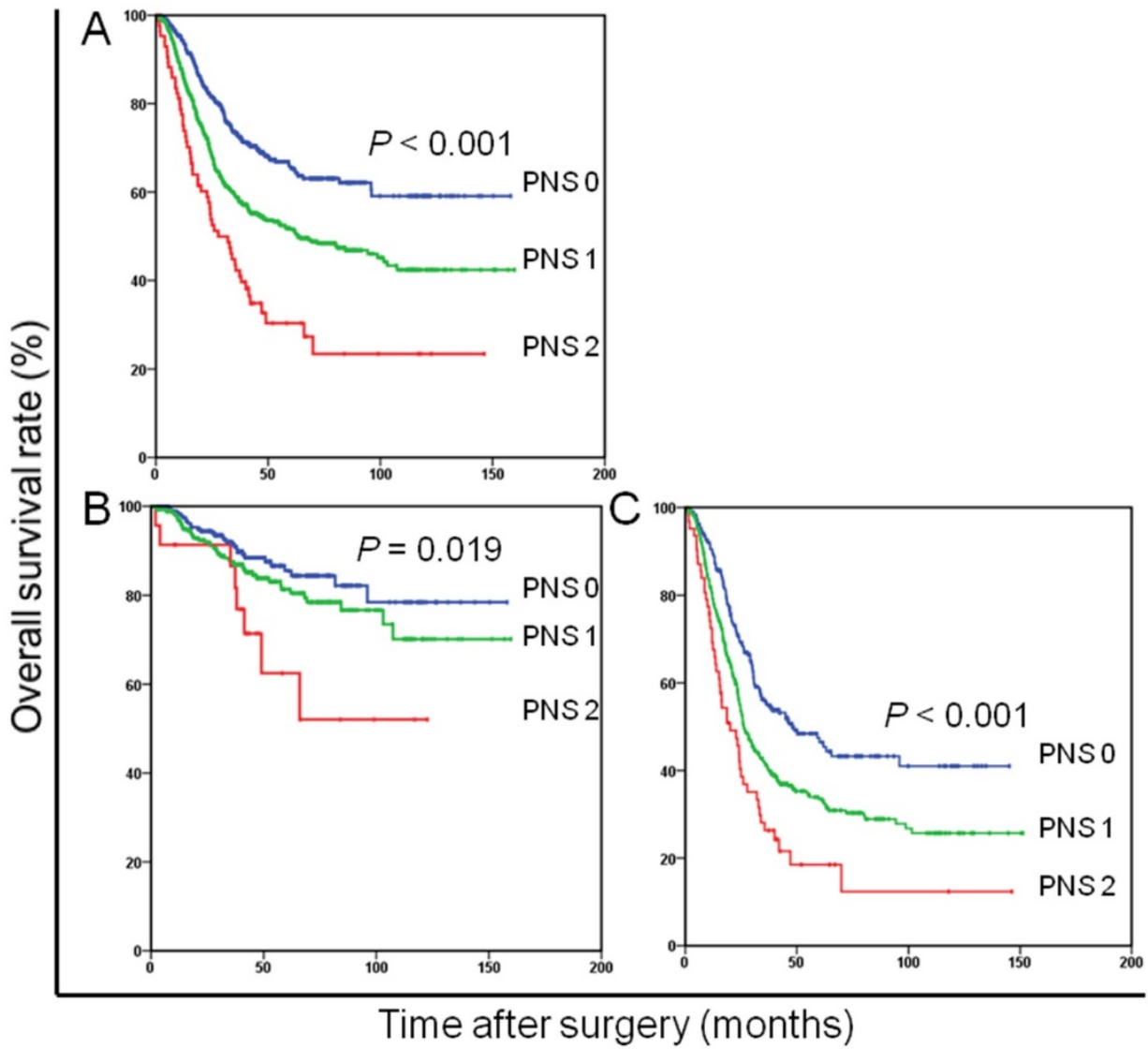

Figure 1. Overall survival based on PNS in patients with stage I-III (A), stage I-II (B), and stage III (C) gastric cancer, respectively. PNS = preoperative nutritional status.

Table 3. Correlation of PNS with clinicopathologic characteristics.

\begin{tabular}{|c|c|c|c|c|}
\hline & PNS 0 & PNS 1 & PNS 2 & $P$ value \\
\hline & $(\mathrm{n}=511)$ & $(\mathrm{n}=722)$ & $(\mathrm{n}=87)$ & \\
\hline Age (years) & & & & 0.015 \\
\hline$<60$ & 294 & 364 & 39 & \\
\hline$\geq 60$ & 217 & 358 & 48 & \\
\hline Sex & & & & $<0.001$ \\
\hline Female & 106 & 279 & 36 & \\
\hline Male & 405 & 443 & 51 & \\
\hline Tumor size $(\mathrm{cm})$ & & & & $<0.001$ \\
\hline$<5$ & 327 & 385 & 23 & \\
\hline$\geq 5$ & 184 & 337 & 64 & \\
\hline Tumor location & & & & 0.366 \\
\hline Upper third & 196 & 287 & 25 & \\
\hline Middle third & 103 & 150 & 20 & \\
\hline Lower third & 212 & 285 & 42 & \\
\hline Histological grade & & & & 0.794 \\
\hline Well differentiated & 90 & 120 & 13 & \\
\hline Poorly differentiated & 421 & 602 & 74 & \\
\hline Anemia & & & & $<0.001$ \\
\hline No & 416 & 475 & 30 & \\
\hline Yes & 95 & 247 & 57 & \\
\hline TNM stage & & & & $<0.001$ \\
\hline I & 120 & 95 & 5 & \\
\hline II & 133 & 180 & 18 & \\
\hline III & 258 & 47 & 64 & \\
\hline Adjuvant chemotherapy & & & & 0.661 \\
\hline No & 204 & 274 & 31 & \\
\hline Yes & 307 & 448 & 56 & \\
\hline
\end{tabular}

Abbreviations: PNS = Preoperative nutritional status; TNM =

tumour-node-metastasis staging.
Subgroup analysis was further performed to assess the relationship between PNS, age, and OS. OS was $60 \%$ and $51 \%$ at 5 years for young ( $<60$ years) and old patients $(\geq 60$ years), respectively ( $p<0.001)$. An elevated PNS was associated with reduced survival of both young and old GC patients. 5-year OS varied from $69 \%$ (PNS 0) to 30\% (PNS 2) for young patients $(\mathrm{P}<0.001)$, and varied from $62 \%$ (PNS 0$)$ to $27 \%$ (PNS 2) for old patients $(\mathrm{P}<0.001$; Figure 2$)$. Similarly, the PNS stratified survival of GC patients irrespective of adjuvant chemotherapy status. 5-year OS for patients who received adjuvant chemotherapy was stratified from 67\% (PNS 0) to 31\% (PNS 2) (P < 0.001 ), and varied from $64 \%$ (PNS 0) to $30 \%$ (PNS 2) for patients who did not receive adjuvant therapy $(\mathrm{P}<$ 0.001; Figure 3). Furthermore, the prognostic significance of PNS was still maintained when stratified by sex, tumor size and anemia (All $\mathrm{P}<0.05$ ). Of note, the PNS was still associated with OS in patients with PNI score 0, serum albumin $\geq 35 \mathrm{~g} / \mathrm{L}$, BMI $\geq 18.5 \mathrm{~kg} / \mathrm{m}^{2}$, or preoperative weight loss $<5 \%$ of body weight, respectively (All $\mathrm{P}<0.05$; Figure 4; Table 5). 
Table 4. Univariate and multivariate analyses of overall survival in 1320 patients undergoing curative resection for gastric cancer.

\begin{tabular}{|c|c|c|}
\hline & Univariate analysis & Multivariate analysis \\
\hline & HR (95\% CI) P-value & HR (95 \% CI) P-value \\
\hline Age (years) & $<0.001$ & $<0.001$ \\
\hline$<60$ & 1.00 & 1.00 \\
\hline$\geq 60$ & $1.494(1.257,1.776)$ & $1.435(1.202,1.711)$ \\
\hline Sex & 0.742 & \\
\hline Female & 1.00 & \\
\hline Male & $1.032(0.857,1.241)$ & \\
\hline Tumor size $(\mathrm{cm})$ & $<0.001$ & 0.852 \\
\hline$<5$ & 1.00 & 1.00 \\
\hline$\geq 5$ & $1.771(1.489,2.106)$ & $0.983(0.819,1.179)$ \\
\hline Tumor location & $<0.001$ & $<0.001$ \\
\hline Upper third & 1.00 & 1.00 \\
\hline Middle third & $0.662(0.527,0.831)<0.001$ & $0.746(0.590,0.944) 0.014$ \\
\hline Lower third & $0.462(0.379,0.563)<0.001$ & $0.573(0.466,0.703)<0.001$ \\
\hline Histological grade & 0.012 & 0.047 \\
\hline Well differentiated & 1.00 & 1.00 \\
\hline Poorly differentiated & $1.379(1.072,1.774)$ & $1.298(1.003,1.680)$ \\
\hline Anemia & 0.069 & \\
\hline No & 1.00 & \\
\hline Yes & $1.186(0.987,1.425)$ & \\
\hline PNI & $<0.001$ & \\
\hline 0 & 1.00 & \\
\hline 1 & $1.746(1.372,2.222)$ & \\
\hline BMI $(\mathrm{Kg} / \mathrm{m} 2)$ & 0.042 & \\
\hline$<18.5$ & 1.00 & \\
\hline $18.5 \leq$ and $<25.0$ & $1.006(0.826,1.224) 0.955$ & \\
\hline $25.0 \leq$ & $0.767(0.613,0.961) 0.021$ & \\
\hline Serum albumin $(\mathrm{g} / \mathrm{L})$ & $<0.001$ & \\
\hline$<35$ & 1.00 & \\
\hline$\geq 35$ & $1.909(1.477,2.468)$ & \\
\hline Preoperative body weight loss & $<0.001$ & \\
\hline$<5 \%$ & 1.00 & \\
\hline$\geq 5 \%$ & $1.831(1.537,2.181)$ & \\
\hline PNS & $<0.001$ & $<0.001$ \\
\hline 0 & 1.00 & 1.00 \\
\hline 1 & $1.677(1.381,2.036)<0.001$ & $1.497(1.230,1.820)<0.001$ \\
\hline 2 & $2.938(2.162,3.993)<0.001$ & $2.434(1.773,3.340)<0.001$ \\
\hline TNM stage & $<0.001$ & $<0.001$ \\
\hline I & 1.00 & 1.00 \\
\hline II & $2.930(1.719,4.994)<0.001$ & $2.407(1.407,4.117) 0.001$ \\
\hline III & $11.285(6.947,18.330)<0.001$ & $9.067(5.530,14.866)<0.001$ \\
\hline Adjuvant chemotherapy & 0.451 & \\
\hline No & 1.00 & \\
\hline Yes & $0.934(0.782,1.115)$ & \\
\hline
\end{tabular}

Abbreviations: PNI = Prognostic Nutritional Index; BMI = body mass index; PNS = Preoperative nutritional status; TNM = tumour-node-metastasis staging.

Table 5. Overall survival based on PNS in subgroup analysis.

\begin{tabular}{|c|c|c|c|c|}
\hline & \multicolumn{4}{|c|}{ Patients [n (\%)] / OS (months) mean (95\% CI) } \\
\hline & PNS 0 & PNS 1 & PNS 2 & P-value \\
\hline PNI & & & & $<0.001$ \\
\hline 0 & $511(43.4) / 107.5(100.6,114.3)$ & $640(54.3) / 86.7(80.4,93.1)$ & $27(2.3) / 53.2(33.4,73.1)$ & \\
\hline $\mathrm{BMI}\left(\mathrm{Kg} / \mathrm{m}^{2}\right)$ & & & & $<0.001$ \\
\hline$\geq 18.5$ & $511(65.3)$ / $107.5(100.6,114.3)$ & $264(33.8) / 59.7(52.5,66.8)$ & $7(0.9) / 28.3(9.8,46.8)$ & \\
\hline Serum albumin $(\mathrm{g} / \mathrm{L})$ & & & & $<0.001$ \\
\hline$\geq 35$ & $511(42.5) / 107.5(100.6,114.3)$ & $660(55.0) / 85.8(79.7,91.8)$ & $30(2.5) / 40.3(29.2,51.4)$ & \\
\hline Preoperative body weight loss & & & & $<0.001$ \\
\hline$<5 \%$ & $511(56.9)$ / $107.5(100.6,114.3)$ & $375(41.8)$ / $94.4(86.3,102.6)$ & $12(1.3) / 34.9(13.2,56.5)$ & \\
\hline
\end{tabular}

Abbreviations: PNI = Prognostic Nutritional Index; BMI = body mass index; PNS = Preoperative nutritional status; a Kaplan-Meier survival analysis. 

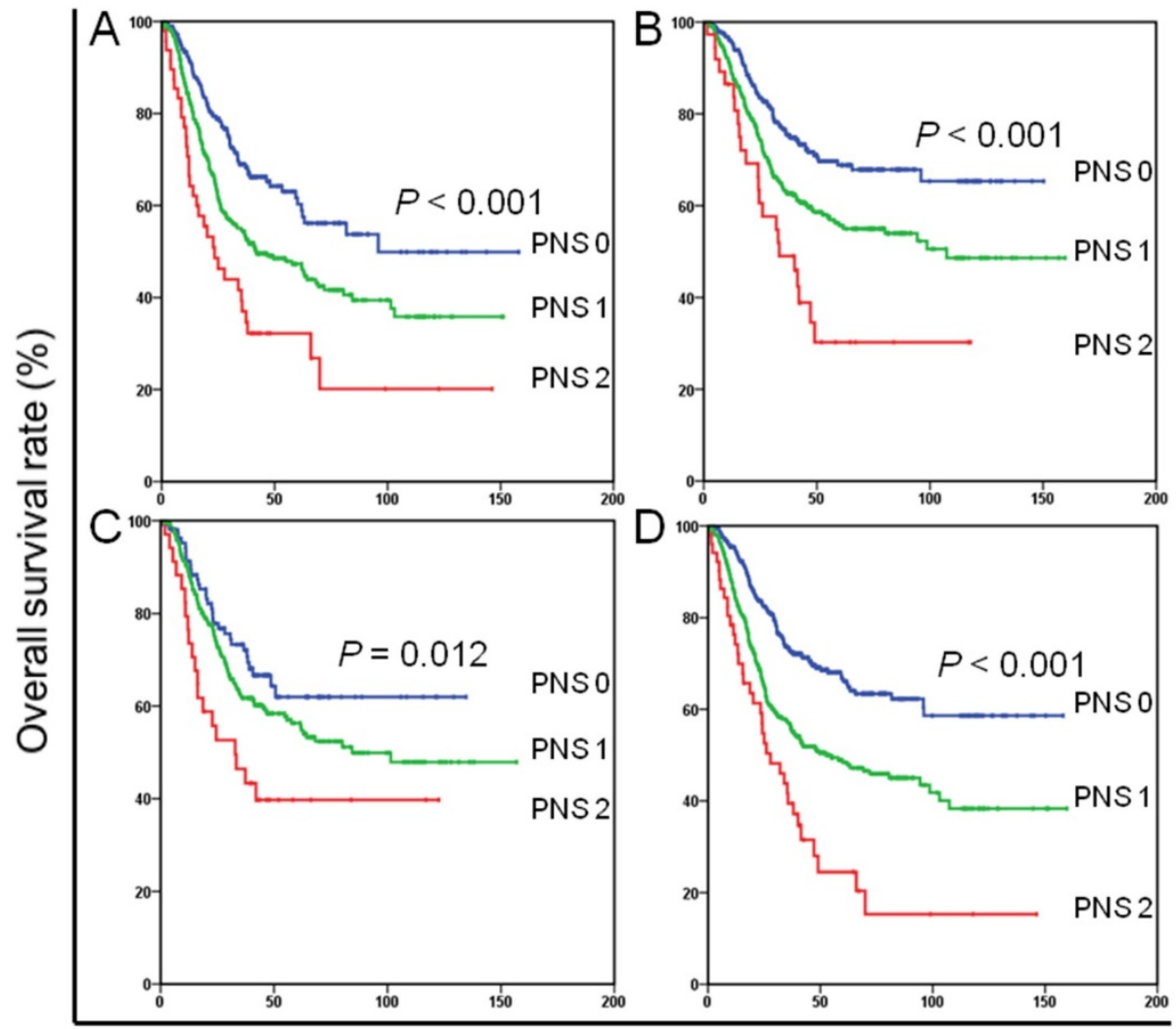

Time after surgery (months)

Figure 2. Overall survival based on PNS in age $\geq 60$ years patients $(A)$, age $<60$ years patients $(B)$, female patients $(C)$, and male patients $(D)$, respectively. PNS $=$ preoperative nutritional status.

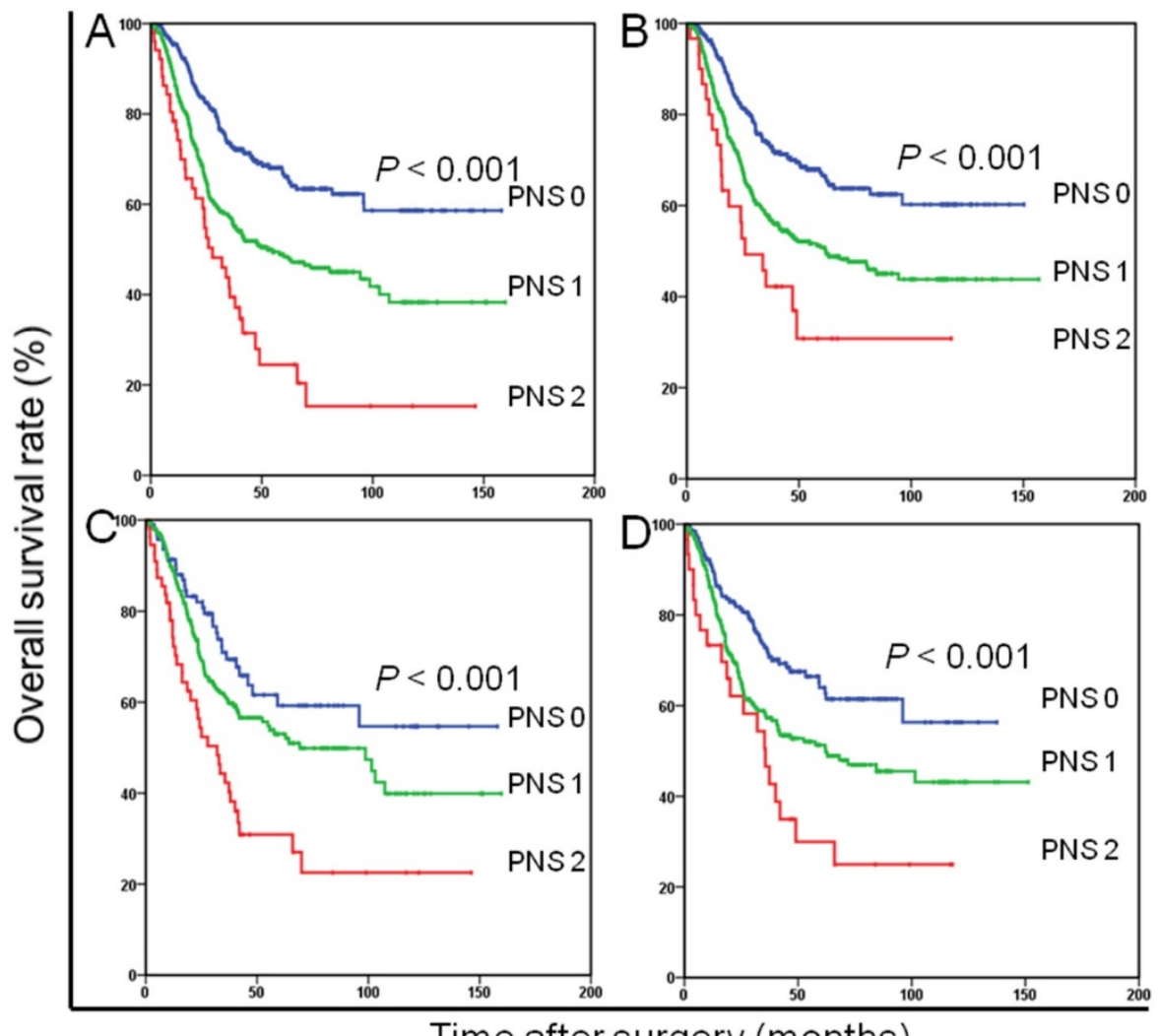

Time after surgery (months)

Figure 3. Overall survival based on PNS in anaemic patients (A), non-anaemic patients (B), patients with adjuvant chemotherapy (C), and patients without adjuvant chemotherapy $(\mathrm{D})$, respectively. $\mathrm{PNS}=$ preoperative nutritional status. 


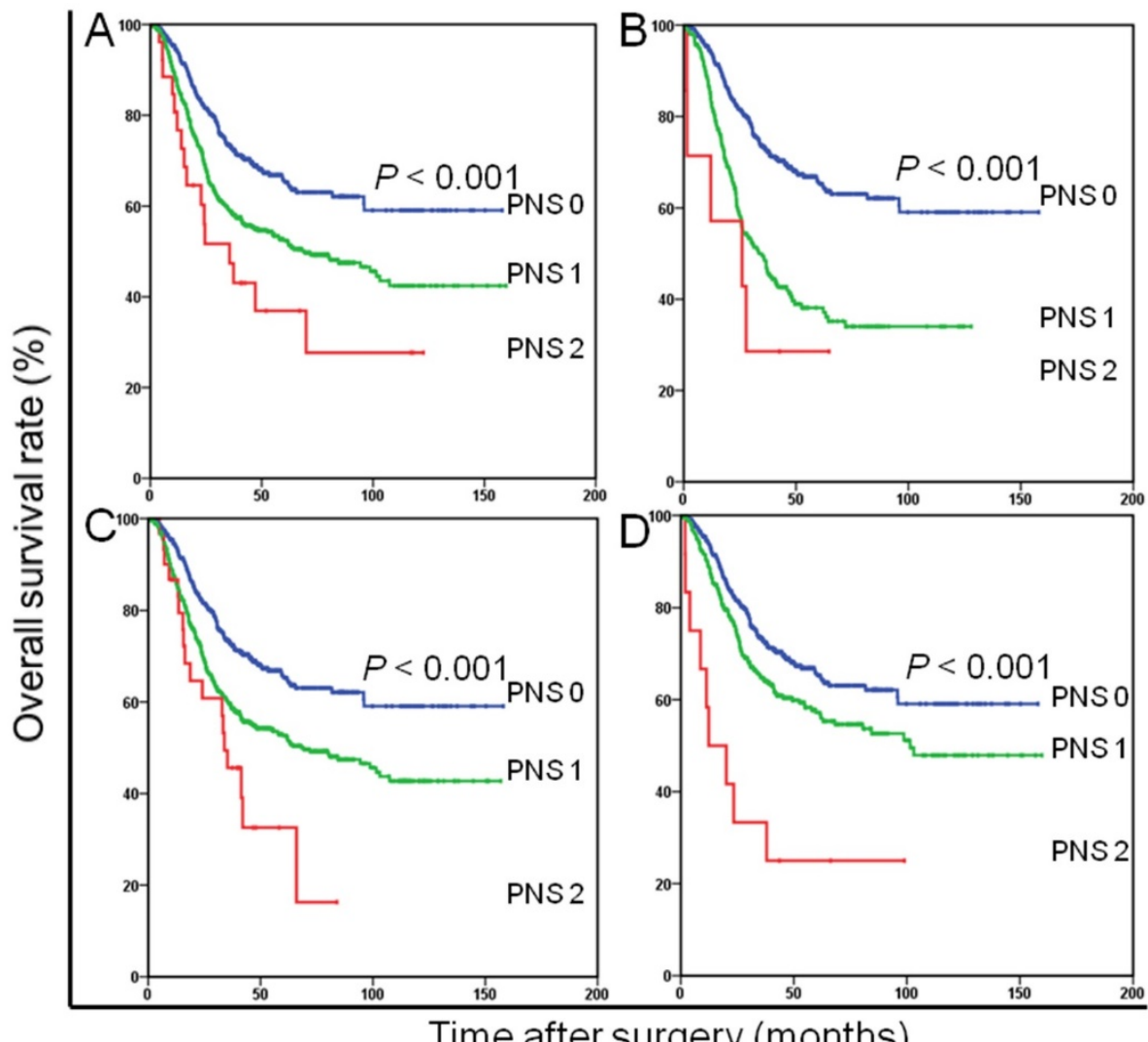

Time after surgery (months)

Figure 4. Overall survival based on PNS in patients with PNI score 0 (A), BMI $\geq 18.5 \mathrm{~kg} / \mathrm{m} 2$ (B), serum albumin $\geq 35 \mathrm{~g} / \mathrm{L}$ (C), or preoperative weight loss $<5 \%$ of body weight $(\mathrm{D})$, respectively. $\mathrm{PNS}=$ preoperative nutritional status; $\mathrm{PNI}=$ Prognostic Nutritional Index; $\mathrm{BMI}=$ body mass index.

\section{Discussion}

Determinants of cancer progression and prognosis are multifactorial and cancer-associated malnutrition is increasingly appreciated to have an important role [23]. Cancer-associated malnutrition is a common but frequently unrecognized problem. Over the past decades, it has been well acceptable that malnutrition is associated with poor response to therapy, greater impairment of quality of life, increased risk of chemotherapy-induced toxicity and poor outcome [24-26]. Thus, clinicians and researchers continue to seek ideal method for identifying malnutrition among cancer patients.

Although the association between nutritional status and prognosis has been clarified in other malignancies, few data exist on the impact of nutritional status in patients undergoing curative resection for GC [27, 28]. Up to now, none of nutritional-based scores has gained widespread consensus in GC. In present study, we developed a new scoring system (PNS), which was derived from PNI, serum albumin, BMI and preoperative weight loss, to identify nutritional risk in GC. We postulated, a combination scoring system might better reflect the balance of nutritional status and provide more important prognostic information than individual indexes.

In present study, we found that the PNS score was independently associated with $O S$ and this association held up in stage I-II and III GC. Furthermore, an elevated PNS was associated with some high-risk clinicopathological characteristics. These findings were supported by other studies, which also found an association between preoperative nutritional status and clinical outcome. Langius et al reported that weight loss both before and during radiotherapy were valuable prognostic indicators for 5-year disease-specific survival in head and neck cancer patients [29]. A recent study shown that preoperative PNI, as a barometer of nutritional status, maybe useful in predicting outcome for patients with GC at stages 1 and 2[30]. Yuko et al found that nutritional status, which was assessed by pretreatment BMI, might be a determinant of prognosis in older GC patients [31]. Given these results, we speculated that the PNS might exert more potent prognostic value than these established nutritional-based scores. Of note, the prognostic significance of PNS was still maintained in various subgroup analyses. Obviously, the PNS, a 
combination scoring system, identified more high-risk patients than individual nutritional-based score.

More importantly, we found that the combination of PNS and TNM stage increased the survival range compared to TNM or PNS alone. Undoubtedly, it could identify more high-risk GC patients undergoing curative resection than TNM stage alone. In clinical practice, with an elevated PNS, early stage patients may need closer follow-up and local advanced patients may require more active adjuvant therapy. Furthermore, patients with an elevated PNS may benefit from preoperative proactive nutritional interventions [32, 33]. Despite promising results of targeted nutritional intervention, no large-scale prospective studies exist assessing the role of nutrition support in GC patients. Future studies, especially prospective randomized controlled studies, are warranted as validation studies.

It should be noted that, of the PNS components, the PNI included serum albumin. When omitting any one variable from the present model, we found it significantly changed the

likelihood ratio and the hazard ratio of the model. Obviously, PNS that includes all four variables was a more comprehensive and superior predictor to identify nutritional risk in GC. In addition, it suggested serum albumin might be a promising prognostic factor in GC and play a key role as part of the PNS composite measure. In fact, our findings were in line with previous study which indicated that albumin alone seemed to be as strong of a predictor of all-cause mortality as the composite measure [34].

A potential limitation of the current study is that it was a retrospective single-centre analysis. However, one benefit of this arrangement was that surgical procedures, laboratory examination, and patient follow-up were consistent during the entire study period. Second, we lacked the data of progression-free survival, though OS was considered the gold standard end-point for cancer prognosis study. Third, there are no established criteria for systematic and structured nutritional evaluation. Therefore, our findings might need to be confirmed with additional outcome measures.

\section{Conclusions}

The PNS, a novel nutritional-based prognostic score, is a powerful prognostic indicator of outcome in patients with GC. It may be a promising tool in directing preoperative nutritional intervention for GC patients.

\section{Acknowledgments}

The authors wish to thank all of the people who helped with this study.

\section{Competing Interests}

The authors have declared that no competing interest exists.

\section{References}

1. Fock KM. Review article: the epidemiology and prevention of gastric cancer. Aliment Pharmacol Ther. 2014; 40: 250-60.

2. Ferlay J, Soerjomataram I, Dikshit R, Eser S, Mathers C, Rebelo M, et al. Cancer incidence and mortality worldwide: sources, methods and major patterns in GLOBOCAN 2012. Int J Cancer. 2015; 136: E359-86.

3. Park JY, von Karsa L, Herrero R. Prevention strategies for gastric cancer: a global perspective. Clin Endosc. 2014; 47: 478-89.

4. Argiles JM. Cancer-associated malnutrition. Eur J Oncol Nurs. 2005; 9 Suppl 2: S39-50.

5. Van Cutsem E, Arends J. The causes and consequences of cancer-associated malnutrition. Eur J Oncol Nurs. 2005; 9 Suppl 2: S51-63.

6. Mullen JT, Davenport DL, Hutter MM, Hosokawa PW, Henderson WG, Khuri $\mathrm{SF}$, et al. Impact of body mass index on perioperative outcomes in patients undergoing major intra-abdominal cancer surgery. Ann Surg Oncol. 2008; 15: 2164-72.

7. van der Schaaf MK, Tilanus HW, van Lanschot JJ, Johar AM, Lagergren P, Lagergren J, et al. The influence of preoperative weight loss on the postoperative course after esophageal cancer resection. J Thorac Cardiovasc Surg. 2014; 147: 490-5.

8. Fiala O, Pesek M, Finek J, Racek J, Minarik M, Benesova L, et al. Serum albumin is a strong predictor of survival in patients with advanced-stage non-small cell lung cancer treated with erlotinib. Neoplasma. 2016.

9. Nourissat A, Mille D, Delaroche G, Jacquin JP, Vergnon JM, Fournel P, et al. Estimation of the risk for nutritional state degradation in patients with cancer: development of a screening tool based on results from a cross-sectional survey. Ann Oncol. 2007; 18: 1882-6.

10. Abd-El-Gawad WM, Abou-Hashem RM, El Maraghy MO, Amin GE. The validity of Geriatric Nutrition Risk Index: simple tool for prediction of nutritional-related complication of hospitalized elderly patients. Comparison with Mini Nutritional Assessment. Clin Nutr. 2014; 33: 1108-16.

11. Ommundsen N, Wyller TB, Nesbakken A, Jordhoy MS, Bakka A, Skovlund E, et al. Frailty is an independent predictor of survival in older patients with colorectal cancer. Oncologist. 2014; 19: 1268-75

12. Yim GW, Eoh KJ, Kim SW, Nam EJ, Kim YT. Malnutrition Identified by the Nutritional Risk Index and Poor Prognosis in Advanced Epithelial Ovarian Carcinoma. Nutr Cancer. 2016: 1-8.

13. Sun K, Chen S, Xu J, Li G, He Y. The prognostic significance of the prognostic nutritional index in cancer: a systematic review and meta-analysis. J Cancer Res Clin Oncol. 2014; 140: 1537-49.

14. Lien YC, Hsieh CC, Wu YC, Hsu HS, Hsu WH, Wang LS, et al. Preoperative serum albumin level is a prognostic indicator for adenocarcinoma of the gastric cardia. J Gastrointest Surg. 2004; 8: 1041-8.

15. Chen HN, Chen XZ, Zhang WH, Yang K, Chen XL, Zhang B, et al. The Impact of Body Mass Index on the Surgical Outcomes of Patients With Gastric Cancer: A 10-Year, Single-Institution Cohort Study. Medicine (Baltimore). 2015; 94: e1769.

16. Liu X, Sun X, Liu J, Kong P, Chen S, Zhan Y, et al. Preoperative C-Reactive Protein/Albumin Ratio Predicts Prognosis of Patients after Curative Resection for Gastric Cancer. Transl Oncol. 2015; 8: 339-45.

17. Japanese Gastric Cancer A. Japanese Classification of Gastric Carcinoma - 2nd English Edition. Gastric Cancer. 1998; 1: 10-24.

18. Washington K. 7th edition of the AJCC cancer staging manual: stomach. Ann Surg Oncol. 2010; 17: 3077-9.

19. Moertel CG, Childs DS, O'Fallon JR, Holbrook MA, Schutt AJ, Reitemeier RJ. Combined 5-fluorouracil and radiation therapy as a surgical adjuvant for poor prognosis gastric carcinoma. J Clin Oncol. 1984; 2: 1249-54.

20. Paoletti X, Oba K, Burzykowski T, Michiels S, Ohashi Y, Pignon JP, et al. Benefit of adjuvant chemotherapy for resectable gastric cancer: a meta-analysis. Jama. 2010; 303: 1729-37.

21. Pinato DJ, North BV, Sharma R. A novel, externally validated inflammation-based prognostic algorithm in hepatocellular carcinoma: the prognostic nutritional index (PNI). Br J Cancer. 2012; 106: 1439-45.

22. White JV, Guenter P, Jensen G, Malone A, Schofield M. Consensus statement: Academy of Nutrition and Dietetics and American Society for Parenteral and Enteral Nutrition: characteristics recommended for the identification and documentation of adult malnutrition (undernutrition). JPEN J Parenter Enteral Nutr. 2012; 36: 275-83.

23. McMillan DC. Systemic inflammation, nutritional status and survival in patients with cancer. Curr Opin Clin Nutr Metab Care. 2009; 12: 223-6.

24. Sala A, Rossi E, Antillon F, Molina AL, de Maselli T, Bonilla M, et al. Nutritional status at diagnosis is related to clinical outcomes in children and adolescents with cancer: a perspective from Central America. Eur J Cancer. 2012; 48: 243-52.

25. von Meyenfeldt M. Cancer-associated malnutrition: an introduction. Eur J Oncol Nurs. 2005; 9 Suppl 2: S35-8. 
26. Zeng Q, Shen LJ, Guo X, Guo XM, Qian CN, Wu PH. Critical weight loss predicts poor prognosis in nasopharyngeal carcinoma. BMC Cancer. 2016; 16: 169.

27. Hendifar A, Osipov A, Khanuja J, Nissen N, Naziri J, Yang W, et al. Influence of Body Mass Index and Albumin on Perioperative Morbidity and Clinical Outcomes in Resected Pancreatic Adenocarcinoma. PLoS One. 2016; 11: e0152172.

28. Gioulbasanis I, Baracos VE, Giannousi Z, Xyrafas A, Martin L, Georgoulias V, et al. Baseline nutritional evaluation in metastatic lung cancer patients: Mini Nutritional Assessment versus weight loss history. Ann Oncol. 2011; 22: 835-41.

29. Langius JA, Bakker S, Rietveld DH, Kruizenga HM, Langendijk JA, Weijs PJ, et al. Critical weight loss is a major prognostic indicator for disease-specific survival in patients with head and neck cancer receiving radiotherapy. Br J Cancer. 2013; 109: 1093-9.

30. Sakurai K, Ohira M, Tamura T, Toyokawa T, Amano R, Kubo N, et al. Predictive Potential of Preoperative Nutritional Status in Long-Term Outcome Projections for Patients with Gastric Cancer. Ann Surg Oncol. 2016; 23: 525-33.

31. Minami Y, Kawai M, Fujiya T, Suzuki M, Noguchi T, Yamanami H, et al. Family history, body mass index and survival in Japanese patients with stomach cancer: a prospective study. Int J Cancer. 2015; 136: 411-24.

32. Perioperative total parenteral nutrition in surgical patients. The Veterans Affairs Total Parenteral Nutrition Cooperative Study Group. N Engl J Med. 1991; 325: 525-32.

33. Smale BF, Mullen JL, Buzby GP, Rosato EF. The efficacy of nutritional assessment and support in cancer surgery. Cancer. 1981; 47: 2375-81.

34. Gregg JR, Cookson MS, Phillips S, Salem S, Chang SS, Clark PE, et al. Effect of preoperative nutritional deficiency on mortality after radical cystectomy for bladder cancer. J Urol. 2011; 185: 90-6. 